\title{
PROSPECÇÃO DE ÁGUA SUBTERRÂNEA NA REGIÃO DE BELÉM (PA) ATRAVÉS DE PERFILAGEM GEOFÍSICA DE POÇO E ELETRORESISTIVIDADE
}

\author{
RONALDO LOPES RODRIGUES MENDES ${ }^{1} \&$ OM PRAKASH VERMA ${ }^{2}$
}

\begin{abstract}
SEARCH OF UNDERGROUND WATER INTHE AREA OF BELÉM (PA) THROUGH GEOPHYSICAL PROFILING OF WELLL AND ELETRORESISTIVITY Today about $46 \%$ of potable water consumed in Belém region comes underground. This shows the importance of this AND ELETRONES source inspite of abundance of surface water in this region (existence of this alternative water resource. In this context, we demonstrate the need to groundwater in Barreiras and the Pirabas formation sediments contribute this alternative water resource. In this context, we demonstrate the need to Electric Soundings (VES) and Geophysical Well Logging, employing gamma rays, spontaneous potential (SP) and electric resistance. Aquifers of two Electlic Soundings (VES) and Geophysical Well Logging, employing garominantly sandy bodies in the from second is constituted of extensive sandy environments are discerned. The first up to about $160 \mathrm{~m}$ of depth whit predomin. The sunerior portion can be explored economically the relativity small

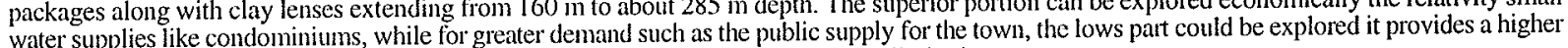
discharge and a good quality water as the deeper aquifers as well protect against pollution's.
\end{abstract}

Keyworts: geophysics, eletroresistivity, well geophysical profiling, underground water, Belém, Pará

\begin{abstract}
RESUMO Hoje, cerca de $46 \%$ da água potável consumida na região de Belém provém dos mananciais subterrâneos, o que mostra a grande Resures existência de uma enorme imporante Neste contexto apresentado, mostra-se quantidade desses recursos nos sedimentos Barreiras e na Formação Pirabas contribui para esta alternativa. Neste contexto apresentado, nostra-se então a necessidade de investigar em tais recursos com o intuito de fazer ótimo proveito destes. Para tanto, foram usadas duas metodologias geofisicas de forma integrada: a Sondagem Elétrica Vertical (SEV) e a Perfilagem Geofísica de Poço, usando raios gama, potencial espontâneo e resistência elétrica. Pode-se dicernir dois ambientes aquíferos. O primeiro até cerca de $160 \mathrm{~m}$ de profundidade, prevalecem corpos arenosos em formas de caéctros bestante extensos com lentes de argila, nal e lentes entrecoitados ou não, imersos en uma matriz argilosa. O segundo é constituído por pacotes arenosó adequado às residências e condomínios, cuja profundidade se estende de $160 \mathrm{~m}$ até $285 \mathrm{~m}$, aproximadamente. O consumo de água da porção superior é adequado às residências e condominas visto o custo elevado de obras de captação a grandes profundidades. Já o abastecimento público deve utilizar a porção inferior, devido as vazón e devido a garantia de água de boa qualidade, protegida de ações antrópicas, como vem sendo feito.
\end{abstract}

Palavras-chave: geofísica, eletroresistividade, perfilagem geofísíca de poço, água subterrânea, Belém, Amazônia

INTRODUÇ̃̃O A demanda para o abastecimento público de água na região metropolitana de Belém tem aumentado cada vez mais e com isso também o uso de água subterrânea, felizmente abundante nesta região, a qual é um recurso de excelente qualidade e com menor custo de captação.

A utilização de diferentes métodos geofísicos na pesquisa hidrogeológica tem sido constante, com intuito de minimizar interpretações ambíguas. Desta forma foram aplicados dois métodos geofísicos: perfilagem geofísica de poço e sondagem elétrica vertical (SEV). Associado a estes, durante a fase de interpretação, foram levadas em consideração as informações geológicas da área. Esta associação se completa no sentido de que o uso de apenas dados geológicos de poço (amostras de calha) acarreta uma grande imprecisão; já a perfilagem tem grande definição vertical mas lateralmente investiga apenas alguns metros ao redor do poço; e a SEV investiga grandes volumes de rocha mas tem limitada resolução vertical das camadas em profundidade.

Desta forma foi realizado um estudo geofísico com o objetivo de conhecer melhor a distribuição e a geometria de aquíferos nesta região, que tem dois grandes conjuntos, o pri- meiro até aproximadamente $160 \mathrm{~m}$ de profundidade, constituído por corpos arenosos das mais variadas dimensões, interdigitados a pelitos, originados possivelmente em planícies de lama de um estuário e gradações laterais também neste sistema, além de ambiente lagunar; o segundo conjunto de aqüíferos se estende a partir de $160 \mathrm{~m}$ de profundidade até, pelo menos, $300 \mathrm{~m}$ aproximadamente e é constituído predominantemente por areias com níveis argilosos, possivelmente formados em ambiente marinho; este seria a melhor ocorrência de água potável da região, servindo ao abastecimento público.

\section{ESTRATIGRAFIA E HIDROGEOLOGIA DA REGIÃO} A estratigrafia do Cenozóico do NE do Pará é composta pela Formação Pirabas e pelos sedimentos Barreiras e Pós-Barreiras, cujas descrições estão sintetizadas na Tabela 1. Os aquíferos da região de Belém foram descritos por Souza e Luiz (1994), e resumida na Tabela 2.

MÉTODOS DE TRABALHO Informações geólógicas e hidrogeológicas indicam corpos sedimentares descontínuos na região de Belém. Com o objetivo de investigar, por métodos 
Tabela 1 - Descrição da estratigrafia da região (Fonte: Farias et al. 1992).

\begin{tabular}{|c|c|c|}
\hline \multicolumn{2}{|c|}{ UNIDADE } & DESCRIÇÃO \\
\hline \multicolumn{2}{|c|}{ Sedimentos Atuais } & $\begin{array}{l}\text { São os sedimentos dispostos ao longo do litoral e vales dos rios e } \\
\text { igarapés. São constituŕlos por areias, siltes e argilas, onde, por } \\
\text { vezes, estes aparecen intercalados. }\end{array}$ \\
\hline \multicolumn{2}{|c|}{ Sedimentos Pós-Barreiras } & 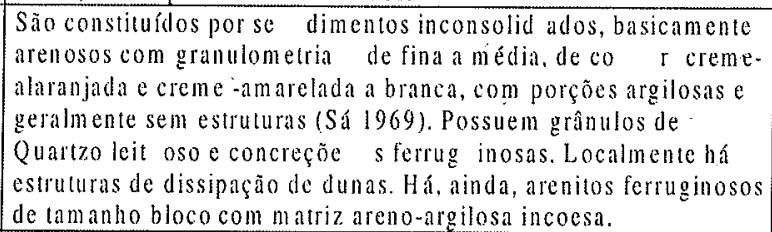 \\
\hline \multicolumn{2}{|c|}{ Sedimentos Barreiras } & $\begin{array}{l}\text { Constituída por sedime ntos continentais argilosos, arenosos } \\
\text { variando até conglomerálicos, pouco consolidados. estratific ados, } \\
\text { de coloração pref erencialmente amarelada e alaranjada e com } \\
\text { nfveis de arenito ferruginoso. Possui ainda fósseis vegetais e } \\
\text { animal. Na regiáo de Belém, estes sedimentos foram dep ositados } \\
\text { cmambiente estuarino. Ne ste contexto foram gerados os sub - } \\
\text { ambientes de plancicie de maré. }\end{array}$ \\
\hline \multirow{3}{*}{ Formação Pirabas } & Fácies Capanema & $\begin{array}{l}\text { Composta por calćrios aggilosos (margas), m icritos e bioclastos, } \\
\text { folhelhos rítmicos e arenilos calciferos, de ambiente lagunar em } \\
\text { borda de bacia ou estuarino. }\end{array}$ \\
\hline & $\begin{array}{l}\text { Fácies Baunilha } \\
\text { Grande }\end{array}$ & $\begin{array}{l}\text { Formada por argilas n egras ou vegetais piritiz ados e nódulos de } \\
\text { calcários eseuros incrustados de crustáceos, depositada em } \\
\text { ambiente redutor, tipicamente de mangue. }\end{array}$ \\
\hline & Fácies Castelo & $\begin{array}{l}\text { Constitúda por calcácios duros diversificados gerado em mar } \\
\text { aberto. }\end{array}$ \\
\hline
\end{tabular}

Tabela 2 - Dados hidrogeológicos da região de Belém.

\begin{tabular}{|c|c|c|c|c|}
\hline Profundidade & Até $50 \mathrm{~m}$ & Entre $50 \mathrm{e} 80 \mathrm{~m}$ & Entre $100 \mathrm{e} 110 \mathrm{~m}$ & $\begin{array}{c}\text { Entre } 135 \text { e } 195 \mathrm{~m} \text { e a } \\
\text { partir de } 205 \mathrm{~m}\end{array}$ \\
\hline $\begin{array}{c}\text { Continuidade } \\
\text { Lateral }\end{array}$ & $\begin{array}{c}\text { Sem continuidade } \\
\text { lateral }\end{array}$ & $\begin{array}{c}\text { Boa continuidade } \\
\text { lateral }\end{array}$ & $-\ldots--$ & $\begin{array}{c}\text { Boa continuidade } \\
\text { lateral }\end{array}$ \\
\hline Vazão & Máxima de $20 \mathrm{~m}^{3} / \mathrm{h}$ & $80 \mathrm{a} 90 \mathrm{~m}^{3} / \mathrm{h}$ & $-\cdots$ & Maiores que $200 \mathrm{~m}^{3} / \mathrm{h}$ \\
\hline Observação & $\begin{array}{c}\text { Teor de ferro menor } \\
\text { que } 0,2 \mathrm{mg} / \mathrm{e} \mathrm{pH} \\
\text { entre } 4,4 \mathrm{e} 6,5(\text { ácido) }\end{array}$ & $\begin{array}{c}\text { Teor de ferro elevado } \\
\text { (maior que } 1,0 \mathrm{mg} / \mathrm{l})\end{array}$ & $\begin{array}{c}\text { Teor de ferro e } \mathrm{pH} \\
\text { dentro dos padrões de } \\
\text { potabilidade }\end{array}$ \\
\hline
\end{tabular}

geofísicos, os aqüíferos, primeiro fez-se a catalogação das perfilagens geofísica dos poços da região, realizadas pelo Departamento de Geofísica (DGf) da UFPA, digitalização e interpretação das mesmas. Os dados de perfilagem - resistência elétrica pontual (RE), raios gama (RG) e potencial espontâneo (SP) - são obtidos usando os equipamentos $1000 \mathrm{C}$ da Mount Sopris e WidCo Model 1200, ambos analógicos com capacidade para perfilar até $400 \mathrm{~m}$. O perfilador $1000 \mathrm{C}$ da Mount Sopris emprega uma única sonda (modelo G375/A). No entanto, as medidas são feitas em duas descidas no poço: na primeira, mede raios gama (RG) e na segunda, resistência elétrica (RE) e potencial espontâneo (SP). As faixas de medidas dos raios gama são ajustáveis entre $5 \mathrm{cps} /$ divisão a $5 \mathrm{Kcps} /$ divisão, as de SP entre $2 \mathrm{mV} /$ divisão a $100 \mathrm{mV} /$ divisão e as de resistência (RE), entre $2 \mathrm{ohm} /$ divisão a $100 \mathrm{ohm} /$ divisão (RE). O perfilador Wid Co 1200 usa duas sondas separadas. Uma para raios gama e outra para SP-RE com faixa de unidade similar ao do perfilador $1000 \mathrm{C}$ da Mount Sopris.

Em seguida, foram realizadas $25 \mathrm{SEVs}$, com abertura de $\mathrm{AB} / 2$ mínima de $130 \mathrm{~m}$ e máxima de $500 \mathrm{~m}$. O equipamento usado foi o resistivímetro modelo R100-A, construído pela Geotest Indústria e Comércio de Equipamentos Eletrônicos, cuja potência nominal de saída é de $100 \mathrm{~W}$. O intervalo de leitura de potencial varia de 0,1 a $199,9 \mathrm{mV}$ e o valor máximo de corrente é de $200 \mathrm{~mA}$, tendo como fonte uma bateria de $12 \mathrm{~V}$ de automóvel.

Em geral, a prospecção geofísica estabelece uma malha em que as estações de medida estejam espaçados a distâncias constantes. Contudo, para a realização de SEVs no meio urbano, essa premissa nem sempre é seguida, uma vez que necessita de ruas não asfaltadas para poder cravar eletrodos, com pouco fluxo de veículos e pedestres para evitar que os cabos sejam partidos ou alguém toque nos eletrodos quando da injeção de corrente. As ruas também devem ser lineares por centenas de metros. Estes fatores dificultaram a pesquisa e contribuíram para que a malha estabelecida fosse irregular e limitaram as aberturas entre os eletrodos A e B. Quanto a disposição dos poços que foram perfilados, também são irregulares, simplesmente porque foram perfurados por empresas de captação de água subterrânea, em geral para abastecimento público ou para 
indústrias, sem intenção de pesquisa e, portanto, dispostos aleatoriamente.

A interpretação dos dados de Perfilagem foi feita utilizando os três perfis juntos (RE, SP e RG) sempre que existentes. Nos aquíferos, o RG é baixo, indicando pouco mineral radioativo, o que entende-se como pouco argilomineral dos folhelhos ou argilitos; a curva do SP desloca-se, indicando que há fluidos nos poros, caso seja para a esquerda, a salinidade da água da formação é maior que a do líquido filtrado da lama, caso seja para a direita a água da formação é menos salgada que o concentrado da lama; o RE é elevado, o que leva a crer que o intervalo observado não possui minerais condutivos como argila, ou seja, provavelmente composto por areia/arenito limpo. E será tão mais limpo quanto maior a resistência. Em rochas ou sedimentos impermeáveis como folhelhos ou argilitos o RG é elevado, o SP não se desloca e o RE é baixo. Posteriormente os perfis foram correlacionados lateralmente. A interpretação não teve a pretensão de definir as rochas ou sedimentos atravessados pela sonda, mas indicar se estes eram ou não permo-porosos.

Quanto as SEVs, o processamento contou com a associação das curvas em famílias, em seguida um ajuste inicial destas curvas de campo, o que implica em suavizá-las. Posteriormente criaram-se modelos geoelétricos de camadas horizontais e contínuas da subsuperfície, usando para isso o método direto, onde as curvas das sondagens foram calculadas através do programa EGSLIB/SEV ID desenvolvido por Rijo (1994a) e comparadas visualmente com as curvas de campo e as informações geológicas disponíveis. Este controle evita ambigüidades, pois uma curva pode representar vários modelos geoelétricos. Tais modelos correspondem a valores de resistividade e espessura das camadas. Em seguida, fez-se o refinamento de tais modelos, através do programa de inversão EGSLIB/SEVIDINV (Rijo 1994b), que usa a técnica de mínimos quadrados. Algumas curvas são mostradas nas figuras 1 e 2 . Após isso fez-se a correlação lateral dos referidos modelos, montagem das seções, ta-

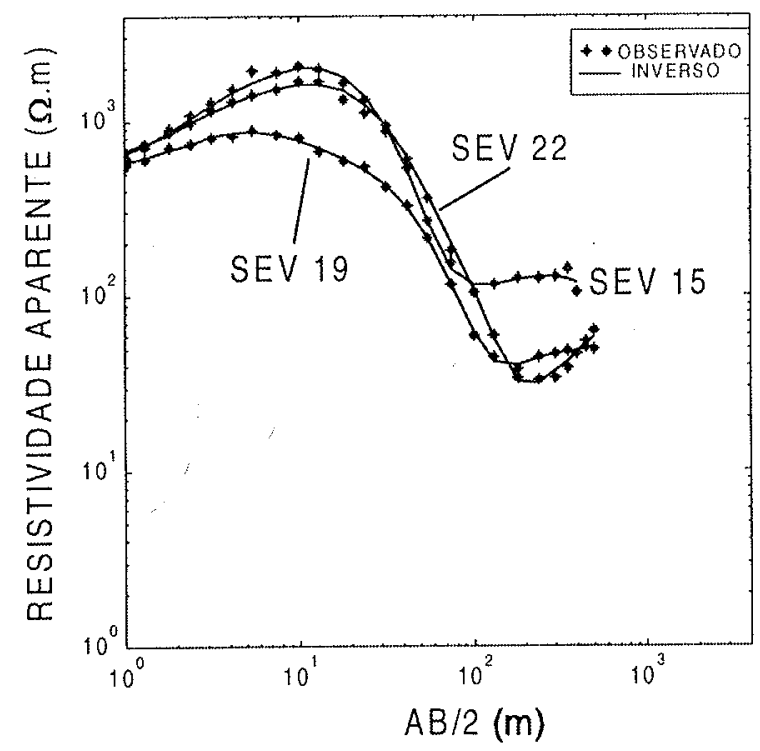

Figura l-Exemplos de familias de curvas de sondagem elétrica vertical.

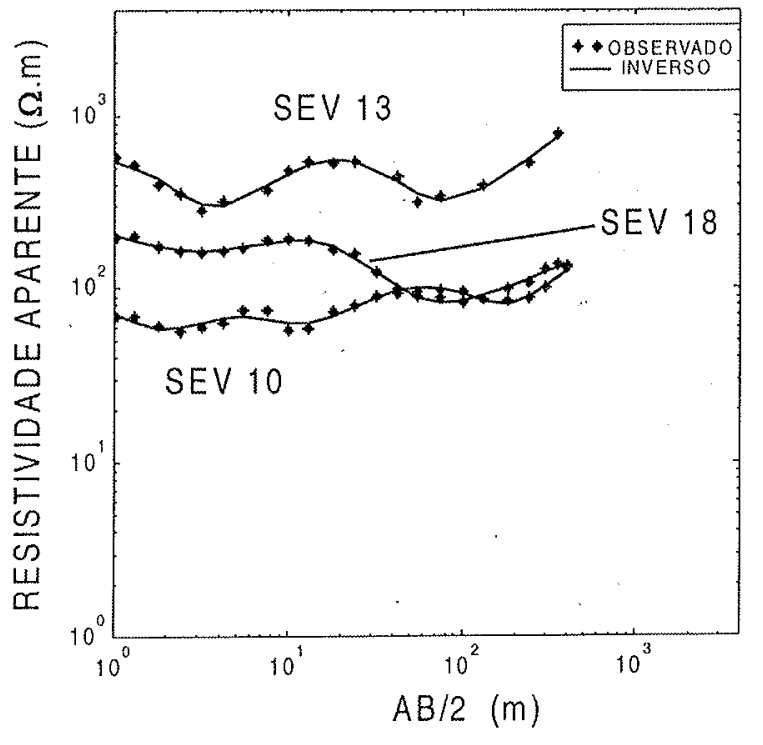

Figura 2 - Exemplos de familias de curvas de sondagem elétrica vertical.

refa ajudada enormemente pelas informações geológicas da região levantadas através da bibliografia.

Ao final do processamento é nítida a complexidade da geologia em questão, como foi descrito anteriormente, exibindo variações laterais, indicadas pelas variadas formas das curvas.

DISCUSSÃO DOS RESULTADOS Ao analisar os dados em questão, pode-se perceber claramente que a contribuição da perfilagem, em relação a qualidade da informação, é melhor que a da SEV. Primeiro porque a perfilagem tem maior definição nos resultados que fornece; segundo, porque a complexidade geológica da região (corpos sedimentares descontínuos) até aproximadamente $100 \mathrm{~m}$ de profundidade pode conduzir a interpretações errôneas das SEVs, que são baseadas no modelo ID (camadas contínuas e horizontais). E também porque a malha de investigação é irregular, o que pode conduzir a um duplo erro de interpretação das SEVs. A localização das perfilagens e das SEVs é mostrada na figura 3.

Desta forma, baseado na interpretação integrada de dados de perfilagem geolísica de poços, sondagem elétrica vertical e da geologia, foram confeccionadas 4 seções geoelétricas e traduzidas em perfis hidrogeológicos, isto é, camadas permoporosas (horizontes arenosos) e impermeáveis (horizontes argilosos), exibidas nas das figuras 4, 5, 6 e 7 .

Em termos gerais, considerou-se que materiais pelíticos (argila/argilito ou folhelho - impermeáveis) possuem resistividade menor ou igual a $50 \Omega . \mathrm{m}$. Valores superiores a este, em geral, referem-se a areia, grânulo, seixo (materiais permo-porosos), em geral de quartzo, sendo tais valores tão maiores quanto o tamanho dos fragmentos. Contudo, valores pouco acima de 50 $\Omega . m$ correspondem a seqüências compostas por variações entre pelitos e areias, como é visto na SEV 20 (Fig. 6).

É freqüente ocorrer em unidades geoelétricas com baixas resistividades lado a lado de unidades apresentando resistividades médias a elevadas. Isso implica em dizer que os estratos têm sua continuação lateral interrompida, o que induz a infe- 


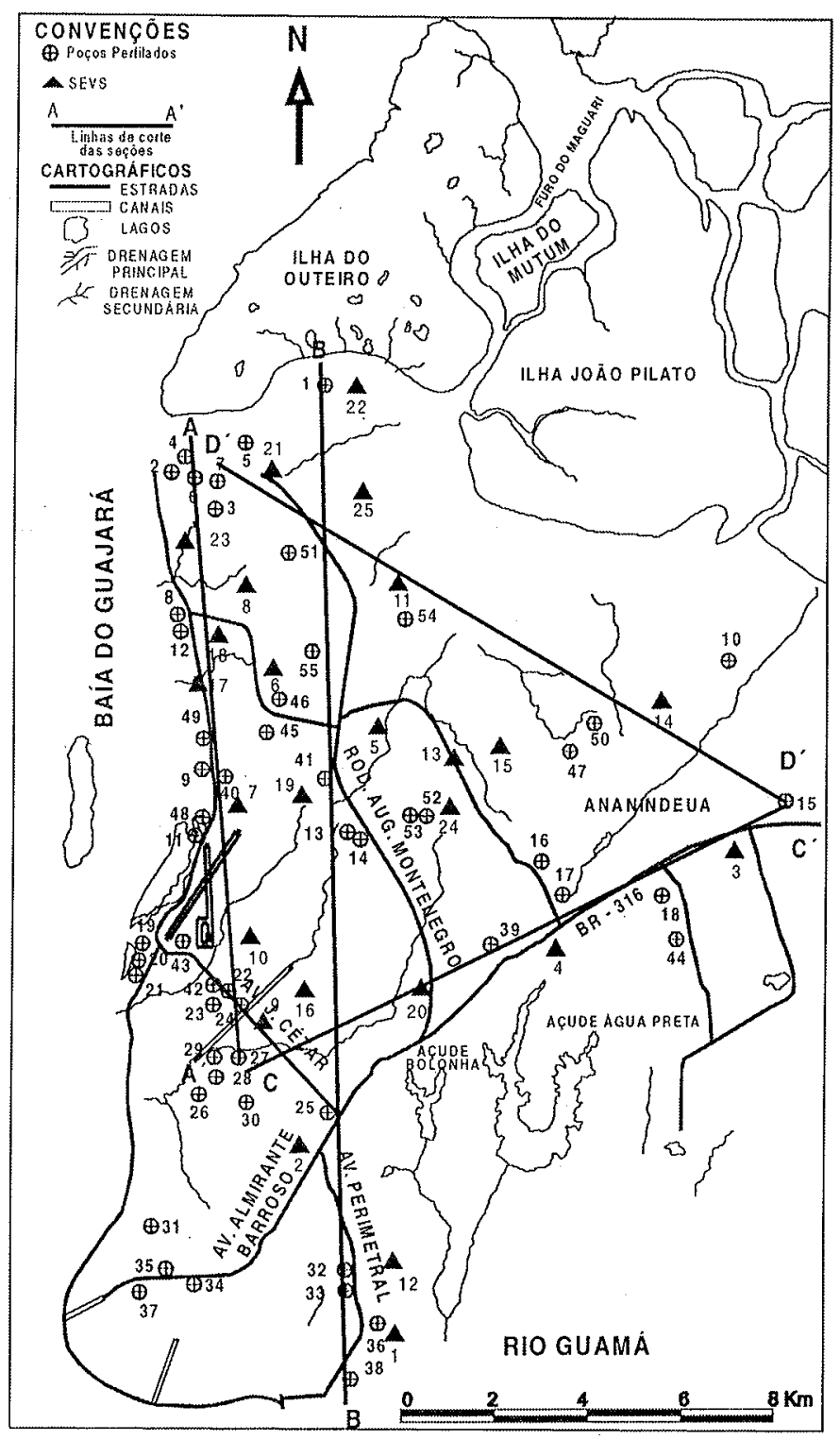

Figura 3 - Mapa de localização dos Poços Perfilados e das SEVS.

rir interdigitação ou gradação lateral, o que resultaria em resistividades variadas à mesma profundidade. Sendo assim, a correlação lateral das unidades geoelétricas é pouco freqüente.

A sucessão vertical de unidades geoelétricas com baixa $e$ alta resistividade também é uma característica geral. Tal variação se dá inclusive em ordem de grandeza.

$\mathrm{Na}$ investigação feita pelas SEVs próximas aos poços perfilados foram definidos horizontes geoelétricos em geral bastante espessos, visto seu baixo poder de resolução, como foi mencionado anteriormente. Já as perfilagens, definiram camadas mais finas dentro de tais horizontes. Esta porção possui sequiências arenosas e pelíticas, muitas vezes interdigitadas. A forma de lente também é muito freqüente, com dimensões nada uniformes. As espessuras variam entre dezenas de metros.

Em geral, o topo das seções é composto por um conjunto de resistividades bastante variadas em função da lixiviação, produto do forte intemperismo da região, que descaracteriza as unidades superficiais e gera um solo de espessura bastante variada. Por isso foram agrupadas em apenas uma unidade geoelétrica.

Na seção AA', pode-se perceber que até a profundidade de aproximadamente $160 \mathrm{~m}$, há úm padrão composicional e hidrogeológico caracterizado pelás descontinuidades dos corpos sedimentares ao longo do perfil, evidenciada pelas perfilagens. A partir de $160 \mathrm{~m}$ pode-se observar a continuidade lateral ao longo de todo o perfill, seja na seção $\mathbf{A A}$ ', seja na seção BB'. Nesta porção, a composição é predominantemente arenosa com intercalações argilosas.

A seção $\mathbf{C C}^{\prime}$ possui apenas 3 poços profundos $(27,39$ e 17 , com $265 \mathrm{~m}, 285 \mathrm{~m}$ e $200 \mathrm{~m}$, respectivamente), separados por vários quilômetros e assim mesmo apresentam continuidade lateral a partir de $170 \mathrm{~m}$ de profundidade, onde prevalece a composição arenosa com níveis argilosos. Na zona superior também repetem-se as descontinuidades observadas nas seções AA' e BB'.

Na seção AA' os estratos acima dos $160 \mathrm{~m}$ são correlacionáveis, localmente, como entre os poços 42 e 27 , de 50 a $80 \mathrm{~m}$ de profundidade, aproximadamente. Na seção CC' entre os poços 27 e 25 , de 23 a $65 \mathrm{~m}$ também tem correlação lateral. Nota-se que tais casos ocorrem geralmente entre poços contíguos, o que mostra que nesta porção a correlação lateral é limitada.

Na seção DD' há mais poços profundos (260 a $285 \mathrm{~m}$ ) e é possível avaliar melhor a continuidade lateral dos corpos sedimentares em profundidade, que ocorre no mesmo limite e possui mesma composição da seção anterior.

As seções (Figs. 4, 5, 6 e 7) mostram perfis rebatidos, ou seja, vários elementos foram deslocados lateralmente em até quilômetros para uma única linha. Por isso, alguns valores de resistividade aparente, como $246 \Omega$ m na SEV 02 (Fig. 06), são muito elevados para uma porção tão argilosa da seção.

De acordo com as características mostradas pela geologia, entende-se que a zona aqüífera acima de $160 \mathrm{~m}$ faria parte dos sedimentos Barreiras, de ambiente estuarino pela descontinuidade dos corpos sedimentares. A porção inferior seria a Formação Pirabas, de ambiente marinho, em função da elevada continuidade lateral. É possível que a porção entre 100 e 160 m corresponda ainda a parte da Formação Pirabas, como considera Pará (1995). Seria uma ou as duas fácies não marinhas desta formação: a fácies Capanema, de ambiente lagunar de borda de bacia ou estuarina, também composta por calcários e contendo fósseis, ou então a Baunilha Grande, bastante argilo$\mathrm{sa}$, formada em mangue e, portanto, ambas sem continuidade lateral significativa.

Resistência transversal Foi realizada também uma análise em mapa do potencial aquífero da região a partir da Resistência Transversal ( $\mathrm{T}$ ). Lembrando que tal parâmetro é vinculado a resistividade e a espessura de cada horizonte, quanto maior o valor de T, maior a possibilidade de encontrar grandes quantidades de água disponível naquela profundidade. As figuras 08 e 09 mostram a variação deste parâmetro nas profundidades de 0 a $50 \mathrm{~m}$ e de 50 a $100 \mathrm{~m}$, respectivamente.

O mapa da figura 8 tem maior abrangência que o da figura 9, visto que parte das SEVs não tem alcance até $100 \mathrm{~m}$. Neste primeiro mapa, os locais mais favoráveis a obtenção de água até $50 \mathrm{~m}$ de profundidade são as porções Centro-Norte, Nordeste e Este da área, onde os valores de T são superiores a 30 mil $\Omega . m^{2}$ e, mais localmente, quase no extremo sul da área, 


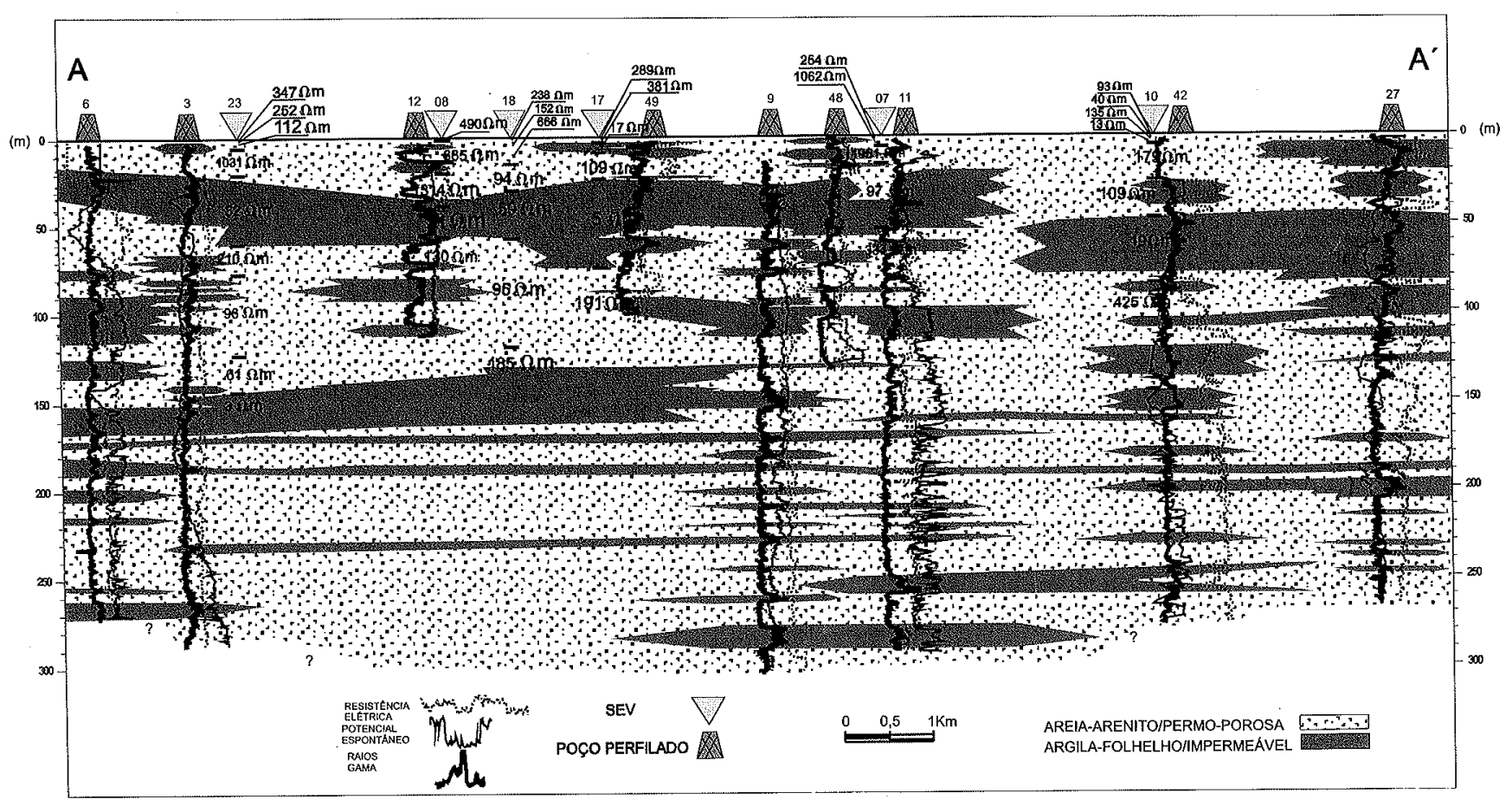

Figura 4 - Perfil hidrogeológico inferido baseado nos dados geofísicos. AA' atravessa a área na direção $N$-S.

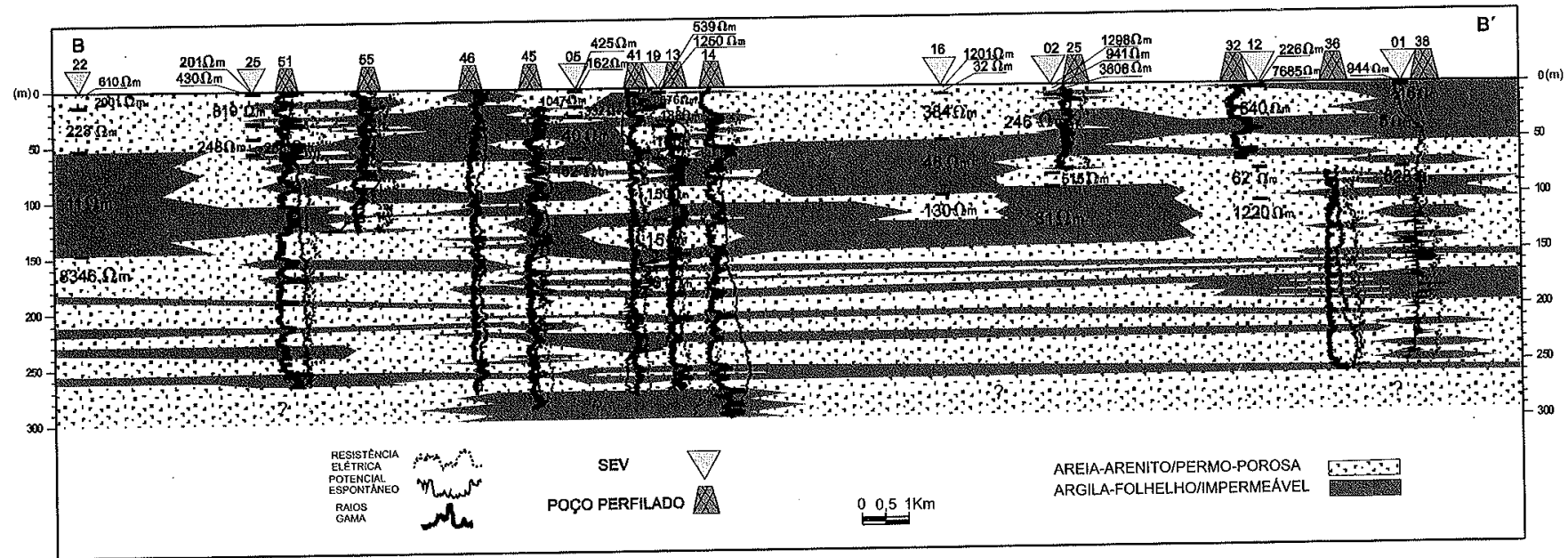

Figura 5-Perfil hidrogeológico inferido baseado nos dados geofísicos. BB' atravessa a área na direção $N$-S.

onde os valores também são significativos.

No mapa da figura 9 as áreas com maior valor de $T$ e portanto com possibilidade de obtenção de água são o extremo sul e o sudeste, com valores superiores a 16 mil $\Omega . \mathrm{m}^{2}$. Pontualmente, ao norte da área, também há valores semelhantes.

É relevante entender que tais mapas têm sua função limitada por dois fatores: 1) pela distribuição irregular das SEVs, visto que quanto mais distribuída, melhor mais representativa a informação e 2) pelo pequeno número de SEVs, pois sabe-se que a interpolação é tão melhor quanto maior a amostragem, ficando isto bem claro quando se observa a amostragem do mapa da figura 9 com oito sondagens a menos que o mapa da figura 8 .

CONCLUSÕES Com base neste estudo pode-se concluir que a região de Belém contém duas zonas aqüíferas distintas. Uma estende até a profundidade em torno de $160 \mathrm{~m}$ com corpos arenosos das mais variadas dimensões, interdigitados a pelitos. Seriam corpos arenosos em meio a planícies de lama de um estuário e gradações laterais também neste sistema. Possivelmente os sedimentos Barreiras e a porção superior da Formação Pirabas (fácies Capanema) foram formados em ambiente lagunar ou estuarino. A fácies Baunilha Grande seria de 


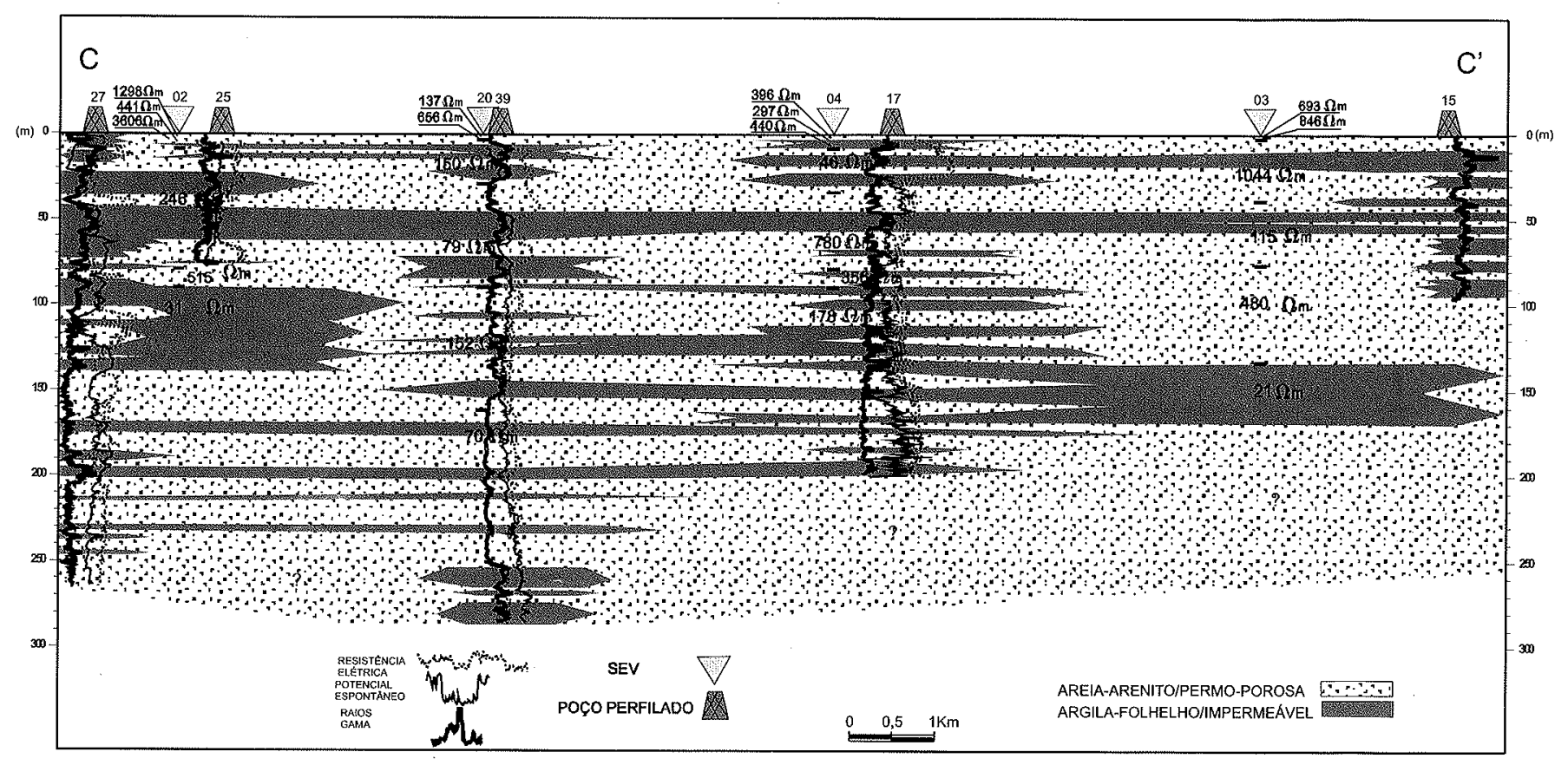

Figura 6-Perfil hidrogeológico inferido baseado nos dados geofísicos. CC'atravessa a área na direção NE-SW.

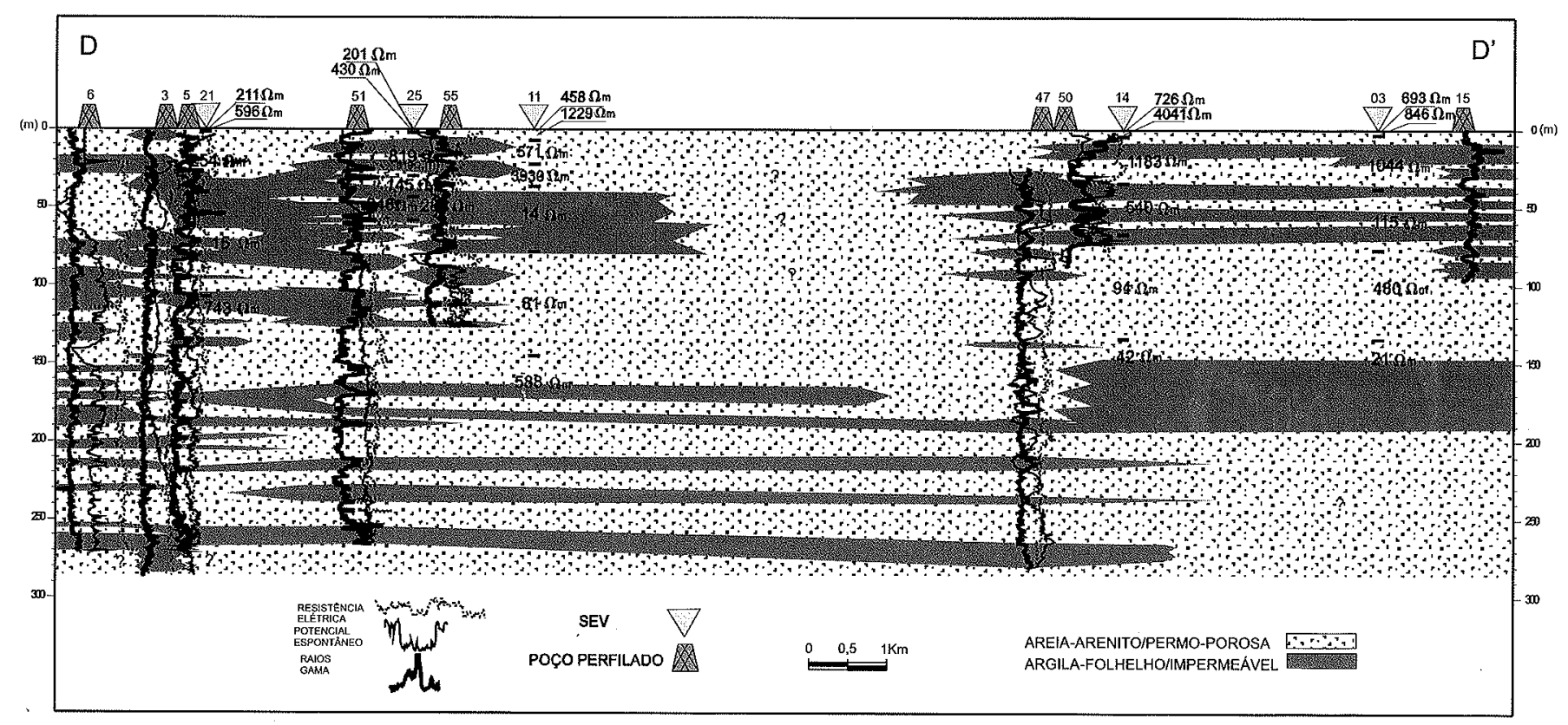

Figura 7 - Perfil hidrogeológico inferido baseado nos dados geofísicos. DD' atravessa a área na direção NW-SE.

ambiente de mangue. A obtenção de água neste nível é razoável, no entanto para abastecimento público pode não ser suliciente visto que os corpos arenosos têm continuidade lateral limitada. Deve-se observar também o teor elevado de ferro a partir dos $50 \mathrm{~m}$ de profundidade, o que inviabilizaria enquanto fonte de água potável, a não ser que algum tratamento seja empregado.
Outra zona se estende a partir de $160 \mathrm{~m}$ até em torno de 300 $\mathrm{m}$ pelo menos. É constituída predominantemente por areias com níveis argilosos. Sua característica principal, a continuidade de seus depósitos por grandes distâncias, induz a interpretar um possível ambiente deposicional marinho. Seria a fácies Castelo da Formação Pirabas, gerada em mar aberto. Esta seria a melhor ocorrência de água potável da região, com gran- 


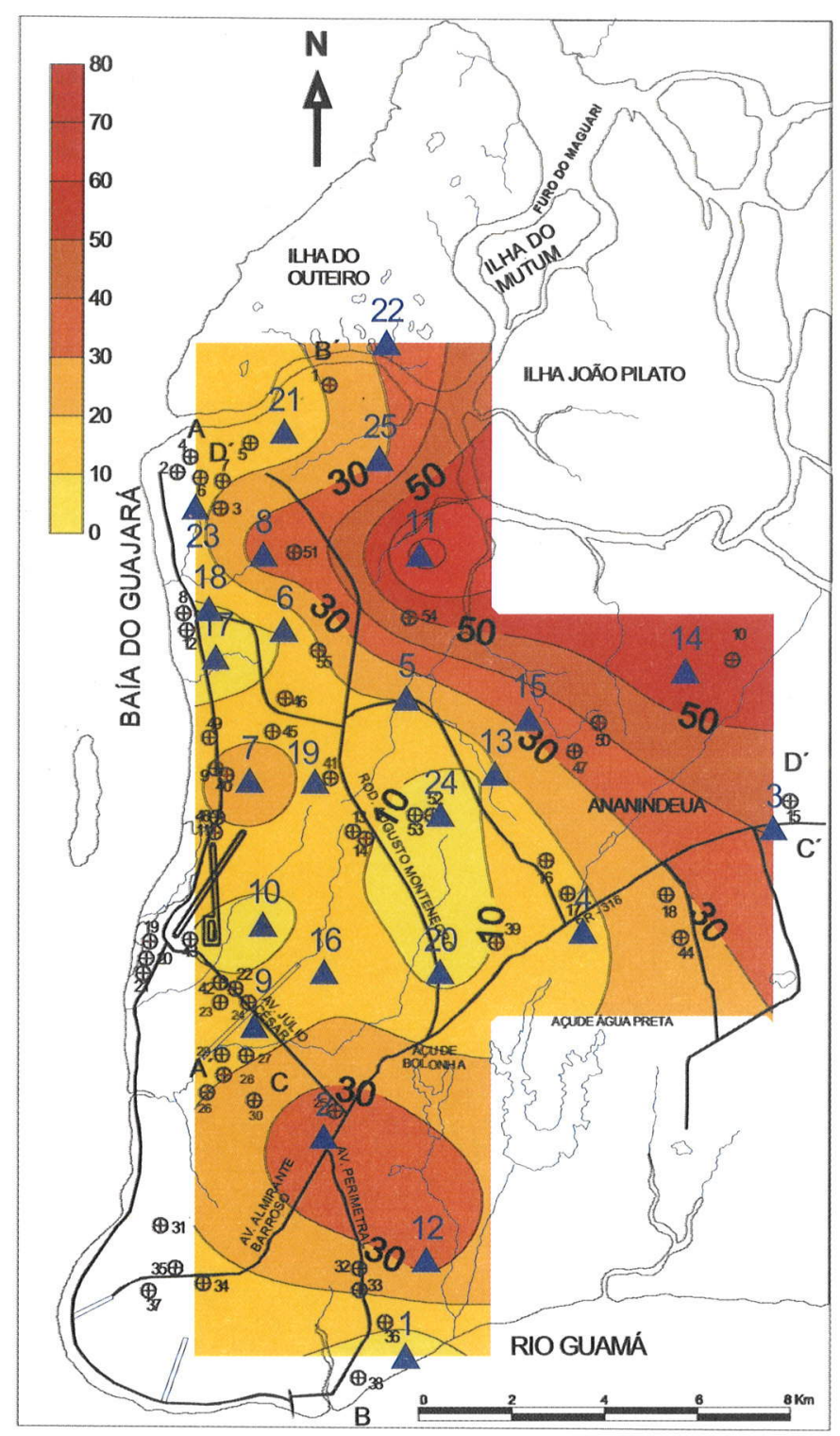

Figura 8-Mapa de Resistência Transversal (em K $\left.\Omega m^{2}\right)$ dos horizontes geoelétricos entre 0 e $50 \mathrm{~m}$ de profundidade.

de volume de armazenagem e livre de estorvos antrópicos superficiais, servindo ao abastecimento público.

Aplicações de métodos geofísicos, em particular de

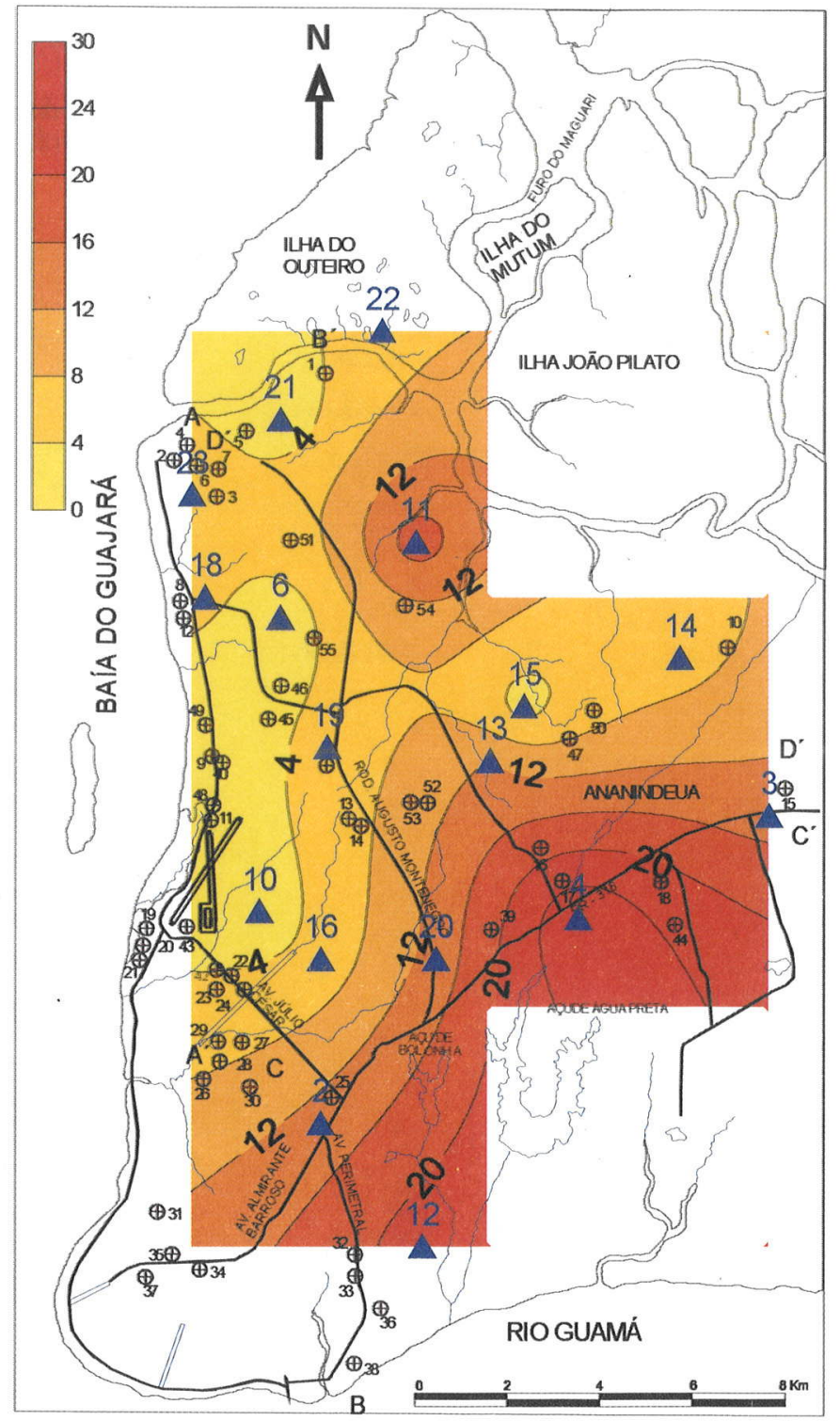

Figura 9-Mapa de Resistência Transversal (em $\mathrm{K} \Omega \mathrm{m}^{2}$ ) dos horizontes geoelétricos entre 50 e 100 m e profundidade.

perfilagem geofísica de poço e sondagem elétrica vertical, de forma integrada aos conhecimentos geológicos, fornecem informações hidrogeológicas mais apuradas.

\section{Referências}

Farias E.S., Nascimento F.S., Ferreira M.A.A. 1992. Estágio de Campo III. Relatório Final. Área Belém/Outeiro. Belém, Centro de Geociências. Universidade Federal do Pará. 247 p.

Pará. Secretaria de Estado de Indústria, Comércio e Mineração; Fundação Instituto Brasileiro de Geografĩa e Estatística. 1995. Plano Diretor de Mineração em Áreas Urbanas. Região de Belém e adjacências: projeto estudo do meio ambiente em sítios de material de construção na região de Belém - Benevides, Estado do Pará, relatório final. Belém. 157 p.

Rijo L. 1994a. SEV1D. Programa para modelagem de sondagem elétrica vertical unidimensional. EGGSLIB (Electrical Geophysics Software Library). Belém, DGF/ UFPa.

Rijo L. 1994b. SEV IDINV. Programa para inversão de sonda- 
gem elétrica vertical unidimensional. EGGSLIB (Electrical Geophysics Software Library). Belém, DGF/ UFPa.

Souza C.W.M \& Luis J.G. 1994. Aqüíferos na região de Belém: um estudo com base em perfilagem de poços. Bol.
M.P.E.G., Ciências da Terra, Belém, 6:31-52.

Manuscrito A-1224

Recebido em 19 de abril de 2001 Revisão dos autores em 15 de fevereiro de 2002 Revisão aceita em 19 de fevereiro de 2002 